\title{
Evaluasi Kinerja Bus Rapid Transit Trans Jateng Pada Koridor Purwokerto-Purbalingga
}

\author{
Performance Evaluation of Bus Rapid Transit \\ Corridor Purwokerto-Purbalingga \\ Cremona Ayu Novita Sari ${ }^{1}$, Besty Afriandini ${ }^{2}$ \\ ${ }^{1,2}$ Teknik Sipil-Universitas Muhammadiyah Purwokerto \\ 1ayucremona@gmail.com
}

\begin{abstract}
ABSTRAK
Bus Rapid Transit Trans Jateng Koridor Purwokerto-Purbalingga merupakan moda transportasi massal Dishub Jateng yang beroperasi pada tanggal 18 Agustus 2018. Diharapkan dengan adanya moda transportasi ini mampu mengurangi pertumbuhan kendaraan pribadi di Kota Purwokerto-Purbalingga. Tujuan dari penelitian ini adalah unuk mengevaluasi kinerja BRT Trans Jateng Koridor Purwokerto-Purbalingga. Penelitian ini bertujuan untuk mengetahui apakah kinerja BRT sudah sesuai dengan standar yang ada. Penelitian dilakukan pada hari Selasa dan Kamis mewakili hari kerja dan hari libur, dimulai pukul 06.00 sampai pukul 18.00. Standar yang digunakan yaitu World Bank dan SK Dirjen Perhubungan Darat Nomor 687 Tahun 2002. Dari hasil penelitian didapatkan load factor sebesar 70\%, kecepatan perjalanan pada saat on peak $49,18 \mathrm{~km} / \mathrm{jam}$ dan off peak sebesar $46.9 \mathrm{~km} / \mathrm{jam}$, waktu tempuh pada saat on peak selama 1 jam 05 menit sedangkan off peak sebesar 2 jam 8 menit, headway pada saat on peak selama 15 menit sedangkan pada saat off peak selama 20-25 menit, sedangkan indikator yang masih belum memenuhi SPM adalah jarak antar shelter sebesar 2640 meter. Untuk indikator yang tidak memenuhi standar maka dapat dilakukan dengan penambahan jumlah shelter agar jaraknya tidak terlalu jauh sehingga sesuai SPM.
\end{abstract}

Kata kunci: Bus Rapid Transit Trans Jateng Koridor Purwokerto-Purbalingga, Standar Pelayanan Minimum,

\begin{abstract}
The Central Java Bus Rapid Transit Corridor Purwokerto-Purbalingga is a mass transportation mode of Dishub Central Java which operates on August 18, 2018. It is expected that with this transportation mode it can reduce the growth of private vehicles in the City of Purwokerto-Purbalingga. The purpose of this study was to evaluate the performance of the Trans Jateng BRT Corridor Purwokerto-Purbalingga. This study aims to determine whether BRT performance is in accordance with existing standards. The study was conducted on Tuesday and Thursday representing workdays and holidays, starting at 6:00 to 18:00. The standard used is the World Bank and SK Director General of Land Transportation Number 687 of 2002. From the results of the study found a load factor of 70\%, travel speed at peak times of $49.18 \mathrm{~km} /$ hour and off peak of $46.9 \mathrm{~km} /$ hour, time travel when on peak for 1 hour 05 minutes while off peak is 2 hours 8 minutes, headway when on peak for 15 minutes while on off peak for 20-25 minutes, while indicators that still do not meet the SPM are the distance between shelters by 2640 meters. For indicators that do not meet the standards, it can be done by increasing the number of shelters so that the distance is not too far so according to SPM.
\end{abstract}


Keywords: Bus Rapid Transit Trans Central Java Corridor Purwokerto-Purbalingga, Minimum Service Standards.

\section{PENDAHULUAN}

Kota Purwokerto merupakan Ibukota dari Kabupaten Banyumas dan Purbalingga merupakan kabupaten yang wilayahnya terletak disebelah Timur Purwokerto kedua daerah tersebut terletak di Provinsi Jawa Tengah. Jumlah penduduk di Purwokerto maupun Purbalingga terus mengalami peningkatan. Semakin meningkatnya jumlah penduduk, maka aktivitas ekonomi dan sosial menjadi tinggi, sehingga mengakibatkan arus lalu lintas dan mobilitas yang tinggi pula. Selain itu Purwokerto juga menjadi kota pusat bisnis, perdagangan maupun pendidikan. Begitu pula dengan Purbalingga yang mengalami pertumbuhan pesat berkembang menjadi kota wisata, industri dan tidak lama lagi akan memiliki bandara komersial yaitu Bandara Jenderal Soedirman.

Untuk mengimbangi dan menekan laju peningkatan penggunaan angkutan pribadi, harus dilakukan perbaikan sistem angkutan umum berdasarkan kemampuan angkut yang besar, kecepatan yang tinggi, keamanan dan kenyamanan perjalanan yang memadai dan, karena digunakan secara massal, haruslah dengan biaya perjalanan yang terjangkau (Ofyar, 2008).

Dalam UU 22/2009 pemerintah diharuskan untuk memenuhi kebutuhan perjalanan penduduk dengan mengadakan angkutan massal. "Pemerintah menjamin ketersediaan angkutan massal berbasis Jalan untuk memenuhi kebutuhan angkutan orang dengan Kendaraan Bermotor Umum di kawasan perkotaan" (pasal 158 ayat 1). Bus Rapid Transit merupakan suatu tranportasi massal berbasis bus yang memberikan mobilitas perkotaan yang cepat, nyaman, dan hemat biaya pada suatu infrastruktur jalur terpisah, memiliki karakteristik operasional yang cepat dengan frekuensi tertentu serta sistem pemasaran dan layanan pelanggan yang prima (Lioyd, 2002 dan Wright, 2007).

Oleh karena itu, untuk mengetahui kinerja angkutan umum dapat dievaluasi dengan memakai indikator standar pelayanan angkutan umum baik dari standar Bank Dunia (Muhammad Nurfadli, dkk., 2015) maupun pemerintah berdasarkan Pedoman Teknis Penyelenggaraan Angkutan Penumpang di Wilayah Perkotaan Dalam Trayek Tetap Dan Teratur melalui SK Dirjen Perhubungan Darat Nomor 687 Tahun 2002 (Dwi Muryanto., 2016) yang terdiri dari faktor muat (load factor), jumlah penumpang yang diangkut, waktu antara (headway), waktu tempuh, kenyamanan penumpang dan tingkat kepuasan penumpang terhadap pelayanan BRT Trans Jateng.

Penelitian ini menggunakan dua perbandingan standar pelayanan minimum yaitu standar Bank Dunia (World Bank, 1986) maupun SK Dirjen Perhubungan Darat Nomor 687 Tahun 2002. Ukuran kinerja tersebut harus dijaga untuk memastikan kinerja operasional BRT Trans Jateng Koridor Purwokerto-Purbalingga tetap menjadi angkutan massal yang handal.

\section{METODE PENELITIAN}

\section{Pengumpulan Data}

Data sekunder yang dibutuhkan adalah rute BRT Trans Jateng Koridor Purwokerto -Purbalingga, data jumlah kendaraan BRT yang beroperasi serta jumlah penumpang harian baik pada saat weekend (Minggu) maupun weekdays (Selasa). Tarif BRT saat ini sebesar Rp. 4000,00. Dalam penelitian ini, pengambilan data primer dilakukan dengan survei dinamis dengan pencatatan di dalam kendaraan untuk menghitung jumlah penumpang yang menempuh suatu trayek, survei statis menghitung waktu tempuh kendaraan pada setiap arah lalu lintas yang dilakukan didalam bus dan survei kuesioner 
yang disebarkan pada penumpang BRT Trans Jateng Koridor Purwokerto-Purbalingga. Survei dilakukan dengan mengambil sampel pada waktu sibuk (peak) dan waktu lengang (off peak). Pegamatan dilakukan pada pukul 06.00-18.00 WIB (12 jam operasional).

\section{Metode Analisis Data}

Pada tahap ini, data hasil Survei dianalisis kemudian dievaluasi kinerjanya berdasarkan standar pelayanan minimum yang telah ditetapkan berdasarkan standar Bank Dunia (World Bank, 1986) maupun standar yang telah ditetapkan pemerintah berdasarkan Pedoman Teknis Penyelenggaraan Angkutan Penumpang di Wilayah Perkotaan Dalam Trayek Tetap dan Teratur (SK Dirjen Perhubungan Darat Nomor 687 Tahun 2002).

\section{HASIL DAN PEMBAHASAN}

Karakteristik responden berdasarkan kuesioner oleh penumpang BRT Trans Jateng Koridor Purwokerto-Purbalingga. Penumpang dikelompokan dan ditinjau berdasarkan jenis kelamin, tingkat pendidikan, usia, pekerjaan utama dan rata-rata total pendapatan/uang saku per bulan. Berdasarkan karakteristik pengguna perjalanan mayoritas adalah wanita sebesar 59\%, tingkat pendidikan dominan SMA/Sederajat sebesar 52\%, usia dominan 17-20 tahun sebesar 26\%, pekerjaan utama pelajar/mahasiswa sebesar $41 \%$, dengan rata-rata total pendapatan/uang saku per bulan $\leq$ Rp. 1 juta sebesar $38 \%$ sebagaimana pada Tabel 1. Selain itu dari hasil kuesioner diperoleh juga data karakteristik perjalanan yaitu frekuensi, maksud perjalanan, kepemilikan kendaraan, tarif BRT saat ini dan opsi lain jika BRT mengalami keterlambatan.

Berdasarkan karakteristik perjalanan, frekuensi perjalanan responden $<2$ kali sebesar 42\%, maksud perjalanan dominan adalah rekreasi /belanja, kepemilikan kendaraan dominan mempunyai sepeda motor sebesar $72 \%$, tariff BRT saat ini sudah sesuai bagi responden sebesar $87 \%$ dan opsi jika BRT Trans Jateng Koridor PurwokertoPurbalingga terlambat maka responden tetap menunggu sampai BRT dating sebesar $68 \%$ sebagaimana Tabel 2.

Berdasarkan hasil kuesioner adapun usulan perbaikan untuk BRT Trans Jateng Koridor Purwokerto-Purbalingga yaitu halte yang sudah ada agar lebih diperbanyak lagi karena terdapat beberapa halte yang jaraknya terlalu jauh dengan tujuan akhir, headway agar lebih pendek, penambahan jumlah armada maupun rute.

Dari hasil survei on board dapat diperoleh load factor rata-rata terangkut BRT Trans Jateng Koridor Purwokerto-Purbalingga, kecepatan, waktu tempuh dan headway. Load Factor BRT rute Terminal Bulupitu-Terminal Bukateja pada hari libur sudah sesuai dengan Standar Pelayanan Minimum mencapai $87 \%$ pada jam-jam tertentu sedangkan pada hari kerja rata-rata load factor hanya sebesar $8 \%$ seperti pada Gambar 1. 
Tabel 1. Data Karakteristik Responden

\begin{tabular}{|c|c|c|}
\hline No & Data Karakteristik Responden & Persentase (\%) \\
\hline \multirow[t]{3}{*}{1} & Jenis Kelamin & \\
\hline & a. Laki-laki & 41 \\
\hline & b. Perempuan & 59 \\
\hline \multirow[t]{7}{*}{2} & Tingkat Pendidikan & \\
\hline & a. SD/Sederajat & 8 \\
\hline & b. SMP/Sederajat & 14 \\
\hline & c. SMA/Sederajat & 52 \\
\hline & d. Diploma & 5 \\
\hline & e. Sarjana S1 & 17 \\
\hline & f. Lainnya & 4 \\
\hline \multirow[t]{7}{*}{3} & Usia & \\
\hline & a. $\quad<17$ tahun & 21 \\
\hline & b. 17-20 tahun & 26 \\
\hline & c. 20-30 tahun & 16 \\
\hline & d. 30-40 tahun & 17 \\
\hline & e. 40-50 tahun & 11 \\
\hline & f. $>50$ tahun & 9 \\
\hline \multirow[t]{7}{*}{4} & Pekerjaan Utama & \\
\hline & a. Pelajar/mahasiswa & 41 \\
\hline & b. Karyawan (BUMN/Swasta) & 15 \\
\hline & c. Wiraswasta/pengusaha & 18 \\
\hline & d. PNS & 6 \\
\hline & e. TNI/Polisi & - \\
\hline & f. Lainnya & 20 \\
\hline \multirow[t]{7}{*}{5} & Rata-rata total pendapatan/uang saku per bulan & \\
\hline & a. $\quad \leq$ Rp. 1 juta & 38 \\
\hline & b. Rp. 1 juta - Rp. 2 juta & 31 \\
\hline & c. Rp. 2 juta - Rp. 3 juta & 16 \\
\hline & d. Rp. 3 juta - Rp. 4 juta & 9 \\
\hline & e. Rp. 4 juta - Rp. 5 juta & 4 \\
\hline & f. $\quad \geq$ Rp. 5 juta & 2 \\
\hline
\end{tabular}

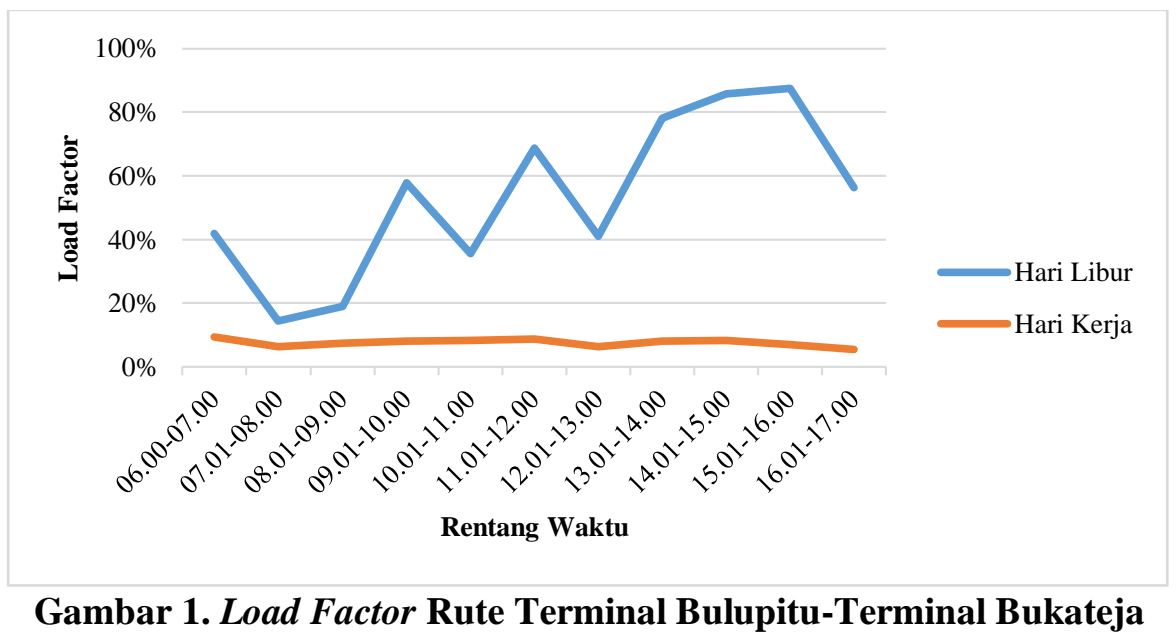

Sedangkan Load Factor rute Terminal Bukateja-Teminal Bulupitu pada hari kerja load factor rata-rata sebesar $52 \%$ sedangkan pada hari libur load factor rata-rata mencapai 
$75 \%$ pada jam puncak siang dan pada jam-jam tertentu bias mencapai $110 \%$ seperti pada Gambar 2.

Tabel 2. Data Karakteristik Perjalanan

\begin{tabular}{ccc}
\hline Karakteristik perjalanan & Item & Persentase (\%) \\
\hline Frekuensi & $<2$ kali & 42 \\
& $3-4$ kali & 29 \\
& $5-6$ kali & 17 \\
Maksud perjalanan & Lainnya & 12 \\
& Pendidikan & 21 \\
& Bekerja & 19 \\
& Berdagang & 11 \\
Kepemilikan kendaraan & Rekreasi/belanja & 28 \\
& Lainnya & 21 \\
\hline Tarif BRT saat ini & Tidak punya & 9 \\
& Mobil pribadi & 10 \\
& Sepeda & 7 \\
& Sepeda motor & 72 \\
& Lainnya & 2 \\
\hline Opsi lain, jika terlambat & Terlalu mahal & 2 \\
& Tetap menunggu sampai datang & 87 \\
& Terlalu murah & 11 \\
\hline & Ganti naik bus lain & 68 \\
\hline & Kendaraan lain & 15 \\
\hline & Tidak jadi pergi & 16 \\
\hline
\end{tabular}

Sumber : Analisis, 2019

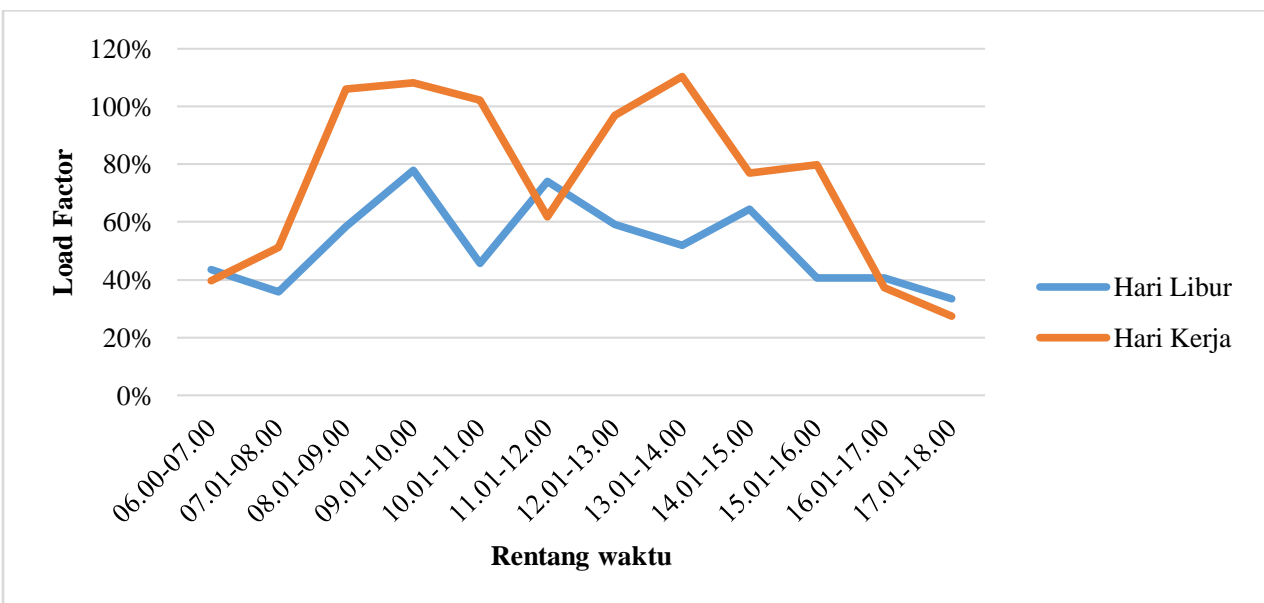

\section{Gambar 2. Load Factor Rute Terminal Bukateja-Terminal Bulupitu}

Data kecepatan BRT Trans Jateng Koridor Purwokerto-Purbalingga dapat dilihat pada Tabel 4 berikut. 
Tabel 4. Kecepatan

\begin{tabular}{lrrrc}
\hline Hari & \multicolumn{2}{c}{ Selasa } & Minggu & \\
\hline Arah & Pwt-Pbg & Pbg-Pwt & Pwt-Pbg & Pbg-Pwt \\
\hline & On peak & Off peak & On peak & Off peak \\
\hline $\begin{array}{l}\text { Total jarak tempuh } \\
\begin{array}{l}\text { (km) } \\
\text { Rata-rata kecepatan } \\
\text { perjalanan(km/jam) }\end{array}\end{array}$ & 26,4 & 39 & 26,4 & 39 \\
\hline Sumber: Analisis, 2019 & 47,36 & 44,88 & 51 & 49 \\
\end{tabular}

Data waktu tempuh BRT Trans Jateng Koridor Purwokerto-Purbalingga dapat dilihat pada Tabel 5 berikut.

Tabel 5. Waktu Tempuh

\begin{tabular}{ccccc}
\hline \multicolumn{1}{c}{ Hari } & \multicolumn{2}{c}{ Selasa } & \multicolumn{2}{c}{ Minggu } \\
\hline & On peak & Off peak & On peak & Off peak \\
\hline Rata-rata (Menit) & 82 & 74 & 129 & 131 \\
\hline Sumber : Analisis, 2019 & & & &
\end{tabular}

Data headway BRT Trans Jateng Koridor Purwokerto-Purbalingga dapat dilihat pada Tabel 6 berikut.

Tabel 6. Headway

\begin{tabular}{lcccc}
\hline Hari & \multicolumn{2}{c}{ Selasa } & Minggu & \\
\hline Arah & Pwt-Pbg & Pbg-Pwt & Pwt-Pbg & Pbg-Pwt \\
\hline & On peak & Off peak & On peak & Off peak \\
Headway (menit) & 15 & $20-25$ & 15 & $20-25$ \\
\hline
\end{tabular}

Sumber : Analisis, 2019

Sedangkan indikator Standar Pelayanan Minimum (SPM) berdasarkan kuesioner yaitu perpindahan moda mayoritar kurang dari 2 kali dan frekuensi BRT per jam pada saat on peak sebanyak 4 buah armada bus dan pada saat off peak sebanyak 3 armada bus sebagaimana Tabel 7 dan Tabel 8.

Tabel 7. Perpindahan Moda

\begin{tabular}{lcc}
\hline Hari & Selasa & Minggu \\
\hline Rata-rata (kali) & $<2$ & $<2$ \\
\hline Sumber : Analisis, 2019 & &
\end{tabular}

Tabel 8. Frekuensi

\begin{tabular}{ccc}
\hline Kode Trayek & \multicolumn{2}{c}{ Frekuensi/ Jam } \\
\cline { 2 - 3 } & On Peak & Off Peak \\
\hline Terminal Bukateja - Terminal Bulupitu & 4 & 3 \\
Terminal Bulupitu - Terminal Bukateja & 4 & 3 \\
\hline Sumber : Analisis, 2019 & \multicolumn{2}{l}{}
\end{tabular}

Evaluasi kinerja BRT Trans Jateng Koridor Purwokerto-Purbalingga dilakukan dengan membandingkan hasil analis dengan standar pelayanan minimum baik dari 
standar Bank Dunia (World Bank, 1986) maupun standar yang telah ditetapkan pemerintah (SK Dirjen Perhubungan Darat No. 687, 2002). Hasil perbandingan dapat dilihat pada Tabel 9.

Tabel 9. Perbandingan Hasil Analisis dengan Standar Pelayanan Minimum

\begin{tabular}{|c|c|c|c|c|c|}
\hline Indikator & Satuan & Kondisi & $\begin{array}{c}\text { SPM } \\
\text { World Bank,1986 }\end{array}$ & $\begin{array}{c}\text { SPM } \\
\text { Dirjen } \\
\text { Perhubungan Darat } \\
\text { No. 687, 2002 } \\
\end{array}$ & $\begin{array}{c}\text { Hasil } \\
\text { Analisis }\end{array}$ \\
\hline \multirow{2}{*}{ Load Factor } & \multirow{2}{*}{$\%$} & On Peak & 70 & - & $70 \%$ \\
\hline & & Off Peak & & - & $34 \%$ \\
\hline \multirow{2}{*}{ Kecepatan } & \multirow{2}{*}{$\begin{array}{l}\mathrm{km} / \\
\mathrm{jam}\end{array}$} & On Peak & $\begin{array}{l}\text { 10-12 (kepadatan } \\
\text { tinggi) }\end{array}$ & - & 49,18 \\
\hline & & Off Peak & $\begin{array}{l}25 \text { (kepadatan } \\
\text { rendah) }\end{array}$ & - & 46,9 \\
\hline \multirow{2}{*}{$\begin{array}{l}\text { Waktu } \\
\text { Tempuh }\end{array}$} & \multirow{2}{*}{ Jam } & On Peak & $1-1,5$ & $1-1,5$ & $\begin{array}{c}1 \text { jam } 05 \\
\text { menit }\end{array}$ \\
\hline & & Off Peak & $2-3$ (maks) & $\begin{array}{c}2-3 \\
\text { (maksimum) }\end{array}$ & $\begin{array}{c}2 \text { jam } 8 \\
\text { menit }\end{array}$ \\
\hline \multirow[b]{2}{*}{ Headway } & \multirow[b]{2}{*}{ menit } & On Peak & $5-10$ & $5-10$ & 15 menit \\
\hline & & Off Peak & $10-20$ (maks) & $10-20$ (maksimum) & $\begin{array}{c}20-25 \\
\text { menit }\end{array}$ \\
\hline \multirow{2}{*}{ Perpindahan } & \multirow{2}{*}{ per trip } & & & 1 & \\
\hline & & & - & 2 (maksimum) & $<2$ kali \\
\hline Frekuensi & per jam & & - & - & 4 \\
\hline \multirow[b]{2}{*}{ Jarak Halte } & \multirow[b]{2}{*}{ meter } & & & $300-500$ & \\
\hline & & & - & $\begin{array}{c}500-1000 \\
\text { (pinggiran kota) }\end{array}$ & 2640 \\
\hline
\end{tabular}

Sumber : Analisis, 2019

Berdasarkan tabel 9 dari segi load factor BRT Trans Jateng Koridor PurwokertoPurbalingga mencapai SPM (Standar Pelayanan Minimal) pada saat on Peak di hari Weekdays. Dilihat dari segi kecepatan BRT sudah diatas Standar Pelayanan Minimum baik pada kondisi on peak maupun off peak. Dilihat dari waktu tempuh saat on peak maupun off peak masih memenuhi dari standar yang ada. Begitu juga dengan headway pada kondisi on peak dan off peak sedikit melebihi dari standar yang ada. Namun, pada kondisi tertentu saat on peak sering terjadi penumpukan jumlah penumpang di shelter hal ini dikarenakan belum adanya kebijakan perihal jalur khusus untuk laju pergerakan BRT sehingga penyebab headway tidak terjaga adalah kendala kemacetan. Perpindahan moda penumpang BRT dari hasil kuesioner lebih dari 2 kali berganti moda. Frekuensi BRT dalam satu jam sebanyak 3 buah armada bus. Sedangkan dilihat dari segi jarak halte masih belum memenuhi standar SPM maupun World Bank beberapa halte mempunyai jarak 1000 meter tetapi ada pula yang mencapai 2640 meter.

\section{KESIMPULAN}

Berdasarkan hasil evaluasi dapat disimpulkan bahwa kinerja BRT Trans Jateng Koridor Purwokerto-Purbalingga secara keseluruhan sudah mencapai Standar Pelayanan Minimum (SPM). Dari hasil penelitian didapatkan load factor sebesar 70\%, kecepatan perjalanan pada saat on peak 49,18 km/jam dan off peak sebesar $46.9 \mathrm{~km} / \mathrm{jam}$, waktu tempuh pada saat on peak selama 1 jam 05 menit sedangkan off peak sebesar 2 jam 8 menit, headway pada saat on peak selama 15 menit sedangkan pada saat off peak selama 
20-25 menit, perpindahan moda per trip < 2 kali, dan frekuensi BRT sebanyak 4 kali per jam, sedangkan indikator yang masih belum memenuhi SPM adalah jarak antar shelter sebesar 2640 meter. Dari indikator kinerja pelayanan yang sudah memenuhi Standar Pelayanan Minimum (SPM) adalah load factor, kecepatan perjalanan, waktu tempuh, headway, perpindahan moda dan frekuensi, sedangkan indikator yang masih belum memenuhi SPM adalah jarak antar shelter. Untuk lebih meningkatkan load factor BRT perlu adanya upaya pemerintah seperti pengurangan bus yang berada di koridor Purwokerto-Purbalingga,dengan mengalihkan ke jalan yang belum terakses angkutan umum maupun penambahan armada pada jam sibuk untuk mengurangi penumpukan penumpang. Perlu adanya penambahan shelter agar jarak antar shelter tidak terlalu jauh. Perlu dilakukan kajian demand dalam satu trayek maupun evaluasi aksesibilitas dan coverage area yang diintegrasikan dengan pola tata guna lahan sehingga BRT Trans Jateng Koridor Purwokerto-Purbalingga dapat mengembangkan armadanya menjadi lebih baik dan menarik lebih banyak orang untuk menggunakan angkutan umum.

\section{DAFTAR PUSTAKA}

Prajitno, A. F. H., Machsus, M., Basuki, R., Arifin, S., Sukobar, S., Moeljono, T., \& Budhi, W. S. (2018). Analisa Pola Perjalanan dan Karakteristik Penumpang Bus Trans Sidoarjo. Jurnal Aplikasi Teknik Sipil, 16(2), 47-54.

Muryanto, D., \& Santosa, R. (2016). Kajian Operasional Bus Rapid Transit (BRT) Koridor Utara Selatan Kabupaten Sidoarjo. Prosiding Temu Ilmiah Ikatan Peneliti Lingkungan Binaan Indonesia, 27, 27-30.

Kementerian Perhubugan Republik Indonesia.. 2002. Standar Pelayanan Minimum (SPM) SK Direktorat Jendral Perhubungan Darat Nomor 687 Tahun 2002 Tentang Angkutan Penumpang Umum di Wilayah Perkotaan Dalam Trayek Tetap dan Teratur. Sekretariat Negara: Jakarta.

Wright, L., \& Fjellstrom, K. (2002). Sustainable Urban Transport Sourcebook for PolicyMakers in Developing Cities.

Muhammad, N., Heriyanto, D., \& Pratomo, P. (2015). Evaluasi Kinerja Angkutan Massal Bus Rapid Transit Pada Koridor Rajabasa-Sukaraja. Jurnal Rekayasa Sipil dan Desain, 3(2), 205-220.

Tamin, O. Z. (2008). Perencanaan, Pemodelan dan Rekayasa Transportasi. Bandung: ITB.

Undang-Undang Republik Indonesia Nomor 22 tahun 2009 Tentang Lalu Lintas dan Angkutan Jalan.

Transport, U. (1986). A World Bank Policy Study. World Bank.

Wright, L., \& Hook, W. (2007). Bus Rapid Transit Planning Guide. Institute for Transportation and Development Policy, New York. 